\title{
An Italian functional genomic resource for Medicago truncatula
} Andrea Porceddu ${ }^{1,6}$, Francesco Panara ${ }^{1}$, Ornella Calderini ${ }^{1}$, Lorna Molinari ${ }^{1}$, Paola Taviani ${ }^{1}$, Luisa Lanfaloni ${ }^{2}$, Carla Scotti ${ }^{3}$, Maria Carelli ${ }^{3}$, Laura Scaramelli ${ }^{3}$, Gianluca Bruschi ${ }^{3}$, Viviane Cosson ${ }^{4}$, Pascal Ratet ${ }^{4}$, Henri de Larembergue ${ }^{5}$, Gerard Duc ${ }^{5}$, Efisio Piano ${ }^{3}$ and Sergio Arcioni* 1

\begin{abstract}
Address: ${ }^{1}$ CNR Istituto di Genetica Vegetale Perugia, via Madonna Alta, 130 Perugia, Italy, ${ }^{2}$ Dipartimento di Biologia Cellulare e Ambientale, Università degli Studi di Perugia, Via Pascoli 06123 Perugia, Italy, ${ }^{3}$ CRA-FLC Centro per le Produzioni Foraggere e Lattiero-casearie, Viale Piacenza 29 -, 26900 Lodi, Italy, ${ }^{4}$ Institut des Sciences du Végétal CNRS bat 23 - Avenue de la Terrasse -, 91198 Gif-sur-Yvette, Cedex -, France, ${ }^{5}$ INRA URLEG Dijon BP86510, 21065 Dijon cedex, France and ${ }^{6}$ Dipartimento di Scienze Agronomiche e Genetica Vegetale Agraria, Università degli Studi di Sassari, via E. de Nicola, 07100 Sassari, Italy

Email: Andrea Porceddu - aporceddu@uniss.it; Francesco Panara - f.panara@fastwebnet.it; Ornella Calderini - ornella.calderini@igv.cnr.it; Lorna Molinari - molorna@yahoo.it; Paola Taviani - paolatav@katamail.com; Luisa Lanfaloni - lanfa@unipg.it;

Carla Scotti - carla.scotti@entecra.it; Maria Carelli - maria.carelli@entecra.it; Laura Scaramelli - biol@iscf.it; Gianluca Bruschi - biol@iscf.it; Viviane Cosson - viviane.cosson@isv.cnrs-gif.fr; Pascal Ratet - Pascal.Ratet@isv.cnrs-gif.fr; Henri de Larembergue - duc@epoisses.inra.fr; Gerard Duc - duc@epoisses.inra.fr; Efisio Piano - efisio.piano@entecra.it; Sergio Arcioni* - sergio.arcioni@igv.cnr.it

* Corresponding author
\end{abstract}

Published: I 5 December 2008

BMC Research Notes 2008, I:129 doi:10.1 186/1756-0500-1-129
Received: 9 June 2008

Accepted: 15 December 2008

This article is available from: http://www.biomedcentral.com/I756-0500/I//29

(C) 2008 Arcioni et al; licensee BioMed Central Ltd.

This is an Open Access article distributed under the terms of the Creative Commons Attribution License (http://creativecommons.org/licenses/by/2.0), which permits unrestricted use, distribution, and reproduction in any medium, provided the original work is properly cited.

\begin{abstract}
Background: Medicago truncatula is a model species for legumes. Its functional genomics have been considerably boosted in recent years due to initiatives based both in Europe and US. Collections of mutants are becoming increasingly available and this will help unravel the genetic control of important traits for many species of legumes.

Findings: Our report is on the production of three complementary mutant collections of the model species Medicago truncatula produced in Italy in the frame of a national genomic initiative. Well established strategies were used: Tntl mutagenesis, TILLING and activation tagging. Both forward and reverse genetics screenings proved the efficiency of the mutagenesis approaches adopted, enabling the isolation of interesting mutants which are in course of characterization. We anticipate that the reported collections will be complementary to the recently established functional genomics tools developed for Medicago truncatula both in Europe and in the United States.
\end{abstract}

\section{Background}

Medicago truncatula has emerged as one of the two model systems for legume species.

The Medicago truncatula consortium (supported by US National Science Foundation and Samuel Roberts Noble
Foundation in the USA, and in Europe, mainly by the European Union) has made significant achievements in genome and EST sequencing with a goal of completion of the gene space in 2008 [1]. The amount of information gained from the sequencing will assist studies related to gene function discovery. At the moment three comple- 
mentary strategies have been chosen to create large mutant collections in M. truncatula: transposon tagging, fast neutron mutagenesis and TILLING. T-DNA tagging, one of the most popular strategies in Arabidopsis, did not represent the best option for $M$. truncatula because of the lack of a high throughput transformation system $[2,3]$. A population of more than 7600 Tnt1 lines was recently published [4] and is being developed as a public resource at the Samuel Roberts Noble Foundation http:// www.noble.org. Functional genomics platforms are also available in Europe at the John Innes Genome Laboratory http://jicgenomelab.co.uk/ which, at the moment, provides access to a large population of deletion tilled lines and tilled lines for reverse genetic screening. Both resources were established during the course of the project "GLIP": Grain Legumes Integrated Project, funded by the European Union http://www.eugrainlegume.com. In addition a large Tnt1 collection (approximately 8000 plants) was established in the Jemalong 2HA background during the same project [5]. In the present paper we will report on three $M$. truncatula mutant collections established in Italy and of their potential benefits to the international scientific community for functional genomic studies. The collections were produced in the frame of the Italian functional genomics project "Post-Genomics of Forage Legumes RBNE018BHE" sponsored by the Italian Ministry of University and Research-Funds for Basic Research (MUR/FIRB).

\section{Findings}

\section{A Tnt I mutant collection}

We have regenerated approximately 1000 Tnt 1 mutant lines following current protocols with minor modifications [6]. A starter line from the R108-1 genotype harbouring 3 Tnt1 insertions was produced via Agrobacterium transformation of the construct Tnk23 [6]; the starter line was used as a source of leaf explants in 6 regeneration experiments. Among the 950 R0 lines producing seed, a random sample of 40 lines from different regeneration events was evaluated for transposition by Southern analysis. The average number of new insertion events was estimated to be 15-20. Considering the average number of insertions and the total number of lines available, the Tnt 1 mutant collection produced represents a sum of approximately $14000-19000$ insertions in the M. truncatula genome. To evaluate the ability of Tnt 1 to target generich regions as reported in the literature $[4,7]$ we recovered Tnt1 FSTs via transposon display protocols [8]. In a small scale experiment 96 FSTs were recovered from 16 plants. BLAST analysis of those FSTs showed that at least $47 \%$ of the insertions are within genes, $27 \%$ are in sequenced but not yet annotated Medicago truncatula BAC clones and $25 \%$ do not show similarity with any sequence in the database [see Additional File 1]. This preliminary molecular analysis of the Tnt1 insertion sites confirms the data from Tadege et al., 2008 [4]; in fact in a larger scale experiment these authors reported an overall FST match with Medicago truncatula sequences in the database of $78.6 \%$, $60.2 \%$ of which had high homology with a range of known genes.

To assess the potential of the mutant collection, forward genetic screens were carried out to identify visible mutant phenotypes. On a relatively large subset of the collection (approx. 600 progenies) the percentage of putative mutants observed were as follows: $4 \%$ shoot morphology, $8.5 \%$ root morphology, $4 \%$ nodules. In addition, genomic DNA was extracted from all the plants of the collection and was arranged for reverse genetic screenings. Because the genome coverage of our Tnt1 population is relatively small compared to other resources we suggest our population as a complement and integration to those already available for reverse genetics screening $[4,5]$.

In depth analysis of a few mutants selected from the collection is in progress. As an example, a mutant showing premature leaf death and loss is reported in Fig. 1. The mutation is inherited as dominant. A preliminary segrega-

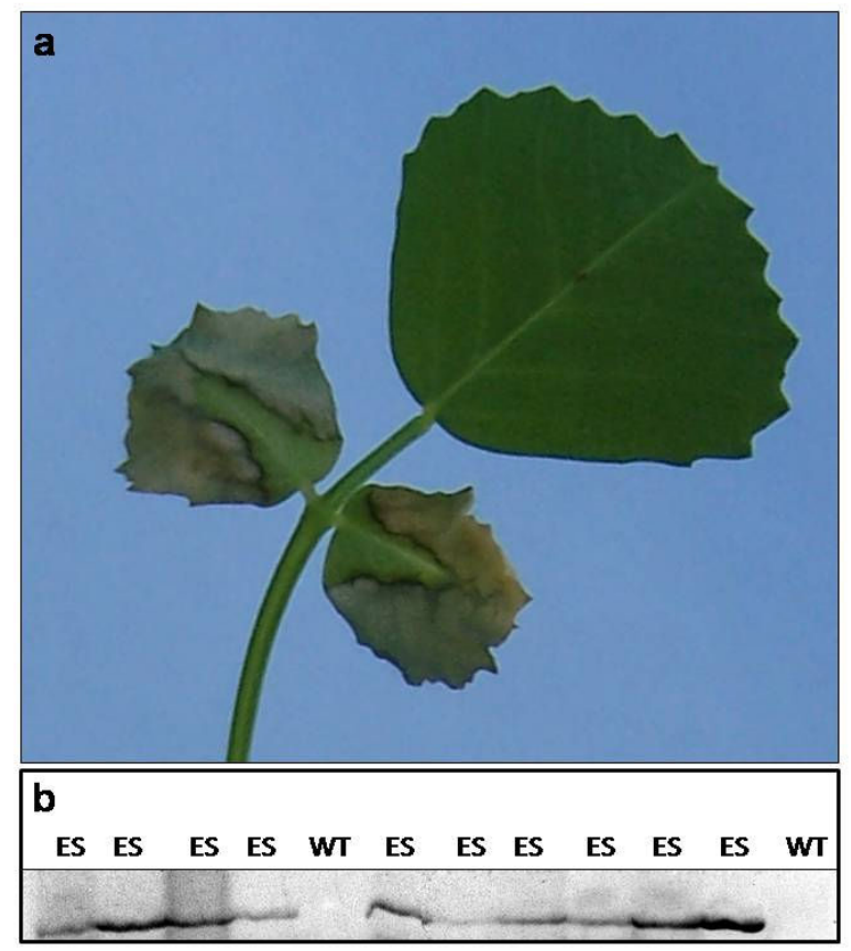

Figure I

a) Leaves of the mutant plant C43 showing symptoms of early senescence. b) retrotransposon display analysis of 12 segregating progenies of $\mathrm{C} 43$ : the band present only in the early senescing plants (ES) was chosen as a candidate gene; (WT = wild type) 
tion analysis based on 10 FSTs recovered from the mutant DNA revealed a candidate gene responsible for the mutation which is a putative component of the RNA interference machinery (Calderini et al, unpubl.).

\section{An activation tagging sample collection}

We report on the production of a small population of activation tagging lines produced as a test of transformation efficiency, which, in spite of its very modest size, allowed us to identify an interesting mutant. The population consists of 128 lines obtained via Agrobacterium transformation of R108-1 genotype with the pSKI074 vector [9] kindly provided by D. Weigel (MPI for Developmental Biology, Tubingen, Germany).

$\mathrm{T} 1$ progenies of the collection were screened for the presence of haemolytic saponins in the leaves using the assay reported in [10]. A mutant plant lacking haemolytic saponins in the leaves was identified. The mutation resulted in the loss-of function of a novel member of the cytochrome P450 family; co-segregation analysis proved that the phenotype is dependent on the mutation identified; an extensive characterization of this mutant is underway (Scotti et al, unpubl.). The involvement of cytochrome P450 in saponin biosynthesis was recently demonstrated in oat roots [11]; we believe that the mutation reported here will help to clarify the biochemical pathway leading to saponin synthesis in Medicago truncatula leaves and it will open possibilities for novel manipulations of such compounds.

\section{A TILLING collection}

M. truncatula seeds from cv. Jemalong genotype 2HA10-93 were treated with $0.15 \%$ EMS [12] to generate a mutant collection. The genotype 2HA10-9-3 was chosen by the European Union as the background of the large scale Tnt1 insertional mutagenesis carried out during the Grain Legumes Integrated Project because of its higher regeneration ability compared to the genotype Jemalong A17 and of its close genetic similarity to the sequenced genotype A17 [13]. Our TILLING population was therefore created in a genetic background that could contribute allelic series for the EU Tnt1 functional genomics platform, whilst also being useful for other genetic backgrounds. The EMS treatment induces numerous point mutations and the generation of these mutants does not require extensive tissue culture work as is the case for the strategies previously reported (Tnt1 and T-DNA tagging). About 2500 M1 plants were grown to produce the M2 generation. M2 seeds were collected from $2281 \mathrm{M} 1$ individuals together with 65 tester plants from the control treatment $(0 \%$ EMS).

The M2 generation (1658 families, represented by 1-5 plants/family for a total of 2560 plants) and 34 tester fam- ilies were grown in a cold greenhouse and phenotypically screened to identify mutants (Table 1, Fig. 2). DNA was extracted from almost all the M2 families and M3 seed has been collected; about 2000 plants are present in the final EMS mutant collection (DNA and M3 seed). DNA samples of equal amount from eight and twelve individual plants were pooled in such a way that each individual was randomly included in both types of bulks; this procedure allows the unambiguous identification of the individual plant carrying the mutation.

The validation of the mutagenic treatment was performed by screening the collection for three genes of interest by the TILLING technique, in collaboration with the Genomic Platform (PGP) of the Parco Tecnologico Padano (Lodi, Italy). The following genes were considered for screening: 1) the cytochrome P450 related to the absence of haemolytic saponins, 2) the M. truncatula phytase gene MtPHY1 [14], and the putative orthologue of the trypsin inhibitor gene MsTI from M. scutellata [15] which was identified by BLASTn searches in GenBank and TIGR M. truncatula Gene Index databases. The amplicons from the putative mutant individuals and from wild type plants were sequenced and compared to analyse single base differences (Table 2).

Different point mutations were found: $\mathrm{G}$ to A transitions (60\%) and $\mathrm{C}$ to $\mathrm{T}$ transitions (40\%) (Tab. 2). The estimated rate of mutation was 1 mutation/Kbp/400 plants, similar to the collection generated by the R. Cook laboratory [16]. In particular for MtPHY1 and the M. truncatula MsTI genes we were able to recover three and six mutants respectively bearing amino acid substitutions. The M3 progenies of the mutant individuals for the three genes of interest are currently subject to phenotypic screening. Moreover 4 alleles were recovered for the cytochrome P450 gene related to the absence of haemolytic saponin phenotype. Three of the mutants recovered carry amino acid substitutions, and one mutant carries a premature stop codon. This allelic series is currently used for genetic complementation tests; two of these mutants were analysed and they lack haemolytic saponins in the leaves in agreement with the role of the reported gene in the pathway. The characterization of the two EMS alleles together with the previously reported loss-of-function mutant underlines the usefulness of the current functional genomics approaches. In-depth analysis of the allelic series regarding the saponin-deficient mutants will be a matter for future publication (Scotti et al., unpub). The TILLING collection reported in the present paper is therefore a valuable tool for the complementation analysis of mutants isolated with other strategies. 


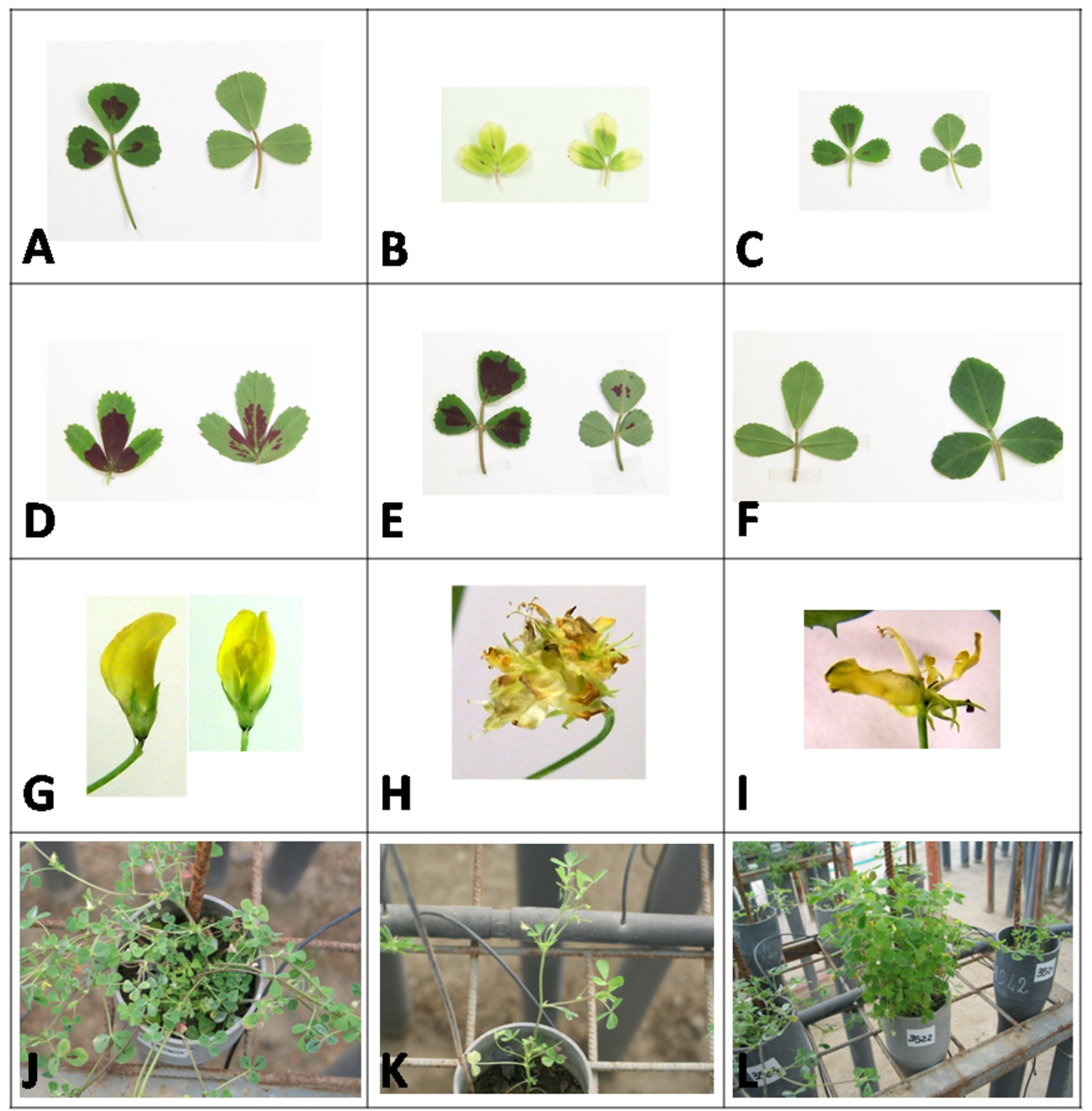

\section{Figure 2}

TILLING collection: a selection of morphological mutants. A-F) leaves of wild type (A) M. truncatula and of mutant (BF) plants showing changes in pigmentation (B), size (C), morphology (D), size of the red spot (E, F). In plates A-E the leaf adaxial side is shown on the left, the abaxial side is shown on the right, in plate $F$ the leaf adaxial side is shown on the right, the abaxial side is shown on the left. G-I) Flowers of wild type plants $(G)$ and of different mutant plants $(\mathrm{H}, \mathrm{I})$ with abnormal floral organs. $\mathrm{J}-\mathrm{L}$ growth habit of wild type plants $(\mathrm{J})$ and of mutant plants (K: no lateral shoots; L: erect stems). 
Table I: Phenotypic classes observed in the screening of the TILLING collection.

\begin{tabular}{|c|c|c|}
\hline Phenotypic class & Number of & Frequency \\
\hline & mutated plants & (\%) \\
\hline \multicolumn{3}{|l|}{ Seedling stage } \\
\hline Albino & 30 & 0.40 \\
\hline Chlorotic & 48 & 0.64 \\
\hline Pale green & 34 & 0.43 \\
\hline Short and compact root & 62 & 0.87 \\
\hline Deformed root (growth-arrested) & 84 & 1.26 \\
\hline Arrested embryos & 781 & 12.3 \\
\hline
\end{tabular}

\section{Adult plant stage}

\section{Plant morphology}

\begin{tabular}{|c|c|c|}
\hline Stunted growth & 145 & 5.66 \\
\hline Very stunted growth & 27 & 1.05 \\
\hline Extreme dwarf, deformed shoots & 2 & 0.08 \\
\hline Extreme dwarf & 41 & 1.6 \\
\hline Extreme short internode & 4 & 0.16 \\
\hline Short internode & 4 & 0.16 \\
\hline Erect stem & 1 & 0.04 \\
\hline Curled stem & 2 & 0.08 \\
\hline \multicolumn{3}{|l|}{ Leaf morphology } \\
\hline Small leaves & 15 & 0.58 \\
\hline Abnormal leaf senescence & 4 & 0.16 \\
\hline Deformed leaves & 24 & 0.94 \\
\hline Partially unifoliate leaves & 1 & 0.04 \\
\hline \multicolumn{3}{|l|}{ Pigmentation } \\
\hline Purple leaves & 1 & 0.04 \\
\hline Pale green leaves & 4 & 0.16 \\
\hline No leaf mark & 9 & 0.35 \\
\hline
\end{tabular}

7229 seeds for the seedling stage and 2560 plants for the adult stage were screened. 
Table 2: TILLING analysis for MtPHYI and the putative M. truncatula orthologue of MsTI from Medicago scutellata

\begin{tabular}{|c|c|c|c|c|}
\hline Gene & GenBank & Primer pair & No. of mutations & Type of mutation \\
\hline MtPHYI & $\underline{\text { AY } 878355}$ & $\begin{array}{l}\text { 5'-AACAATGCCGGTTTCAGGTC } \\
\text { 5'-TTGAAGGCGCAGAAACCTCT }\end{array}$ & 8 & $\begin{array}{l}\mathrm{C} \rightarrow \mathrm{T}(4) \\
\mathrm{G} \rightarrow \mathrm{A}(4)\end{array}$ \\
\hline Trypsin inhibitor & $\underline{A C 135311}$ & $\begin{array}{l}\text { 5'-TGTTTGTTTCGTCTGGAGCA } \\
\text { 5'-GTGGACGGTCTCCCAGACTC }\end{array}$ & 7 & $\begin{array}{l}\mathrm{C} \rightarrow \mathrm{T}(2) \\
\mathrm{G} \rightarrow \mathrm{A}(5)\end{array}$ \\
\hline
\end{tabular}

\section{Conclusion}

We have produced different functional genomic tools for Medicago truncatula that have proved efficient for both forward and reverse genetics in this species. We anticipate the possibility that the reported collections will be of public relevance because they will be accessible to the scientific community. The TILLING and the Tnt1 collections are publicly available for screening via reverse genetics on a cost recovery basis. Forward genetic screenings are ongoing for all the mentioned collections; interested researchers are welcome to enquire in order to organize visits at the host Institutions (CNR-IGV Perugia, CRA-FLC Lodi). For both types of screenings interested scientists are encouraged to contact the corresponding author. At the moment a web site for the reported collections is under construction at http://www.igv.cnr.it. In addition extensive sequencing of FSTs from the Tnt1 collection would be highly desirable also in the frame of future collaborative efforts at the international level. All the sequencing information could be integrated in a public database hosting data of various kinds for the mutants, such as already developed to a high standard for Arabidopsis. Public stock centres such as TAIR and NASC which serve Arabidopsis would be extremely valuable for the Medicago research community. We expect to be able to contribute our collections to such facilities once organized.

\section{Abbreviations}

EST: Expressed Sequence Tag; FST: Flanking Sequence Tag; TILLING: Targeting Local Lesions IN Genomes; EMS: Ethyl-Methane Sulfonate.

\section{Competing interests}

The authors declare that they have no competing interests.

\section{Authors' contributions}

$\mathrm{AP}, \mathrm{FP}, \mathrm{LM}, \mathrm{PT}$ and $\mathrm{OC}$ contributed in plant regeneration and molecular analysis of the Tnt1 collection; OC wrote the paper, AP and SA conceived experiments; AP and LL performed EMS treatment and produced $M 1$ and part of M2 seeds; CS, MC, LS and GB grew the M1 and M2 generations, produced DNA bulks and performed molecular analysis of the activation tagging sample collection; VC, $\mathrm{PR}, \mathrm{HdL}$ and GD performed the phenotypic screening in the Tnt1 collection, EP supervised the work on the TILLING collection.

All authors read and approved the final manuscript.

\section{Additional material}

\section{Additional file 1}

Blast analysis of 96 FSTs from 16 Tnt 1 mutants of Medicago truncatula $R-108$. The data provided represent the Blast analysis of 96 FSTs recovered from 16 plants of Medicago truncatula $R-108$ harbouring the Tnt1 transposon.

Click here for file

[http://www.biomedcentral.com/content/supplementary/17560500-1-129-S1.doc]

\section{Acknowledgements}

The work was supported by the project MUR/FIRB: Post Genomica di Leguminose Foraggere RBNEOI8BHE coordinated by S. Arcioni.

We acknowledge the technical help of: Giancarlo Carpinelli and Marco Guaragno (CNR IGV Perugia, Italy), Giorgio Gnocchi, Annalisa Seminari, Patrizia Gaudenzi and Luisa Ferrari (CRA-FLC Lodi, Italy), Christophe Salon and Virginie Bourion (INRA UMRLEG 102, INRA, Dijon), Vincent Faloya and Estelle Carteret (INRA UE SEDE Glasshouses of Epoisses, INRA, Dijon).

\section{References}

I. Young ND, Roe B, Town C: Insights into Legume genomes from the sequence of Medicago truncatula. Book of Abstract of the 6th European Conference on Grain Legumes Lisbon 12-16 November 2007 :16.

2. Brocard L, Schultze M, Kondorosi A, Ratet P: T-DNA mutagenesis in the model plant Medicago truncatula: Is it efficient enough for legume molecular genetics? CAB Reviews: Perspectives in Agriculture, Veterinary Science, Nutrition and Natural Resources 2006, I(23):7.

3. Brocard L, d'Erfurth I, Kondorosi A, Ratet P: Reverse genetic approaches in Medicago truncatula. In Handbook of New Technologies for Genetic Improvement of Legumes Edited by: Kirti PB. The Haworth Press, Binghampton, New York; 2008 in press.

4. Tadege M, Wen J, He J, Tu H, Kwak Y, Eschstruth A, Cayrel A, Endre G, Zhao PX, Chabaud M, Ratet P, Mysore KS: Large-scale insertional mutagenesis using the Tntl retrotransposon in the model legume Medicago truncatula. Plant / 2008, 54:335-47.

5. Ratet $P$, Angenon $G$, Arcioni S, Atanasson A, Barascud M, Barker Brocard L, Caballero T, Calderini O, Cayrel A, Chabaus M, Cosson V, del Cerro C, den Herder G, Donkova P, Endre G, Ferrandiz C, Goormachtig S, Holsters M, lantcheva I, Jacas L, Kiss E, Krastanova K, Madueno F, Ochatt S, Panara F, Porceddu A, Primard-Brisset C, 
Rakocevic A, Schultze M, Schutz B, Thompson R, Thanh Thu T, Tiritz $H$, Vaughan $D$, Verplancke $C$, Vlahova M: Insertion mutagenesis in Medicago truncatula. The Grain Legume (FP6-GLIP) TntI project. Book of Abstract of the 6th European Conference on Grain Legumes Lisbon 12-16 November $2007: 75$.

6. d'Erfurth I, Cosson V, Eschstruth A, Lucas H, Kondorosi A, Ratet P: Efficient transposition of the Tnt l tobacco retrotransposon in the model legume Medicago truncatula. Plant $J$ 2003, 34:95-106.

7. Tadege M, Ratet P, Mysore KS: Insertional mutagenesis: a Swiss Army knife for functional genomics of Medicago truncatula. Trends Plant Sci 2005, 10:229-35.

8. Ratet P, Porceddu A, Tadege M, Mysore KS: Insertional mutagenesis in Medicago truncatula using Tnt l retrotransposon. Medicago truncatula handbook 2006 [http://www.medicagotruncatula.org/ MedicagoHandbook/index.html].

9. Weigel D, Ahn JH, Blázquez MA, Borevitz JO, Christensen SK, Fankhauser C, Ferrándiz C, Kardailsky I, Malancharuvil EJ, Neff MM, Nguyen JT, Sato S, Wang ZY, Xia Y, Dixon RA, Harrison MJ, Lamb CJ, Yanofsky MF, Chory J: Activation Tagging in Arabidopsis. Plant Physiol 2000, I 22:1003-1014.

10. Jurzysta M: Haemolytic micromethod for rapid estimation of toxic alfalfa saponins. Acta Agrobot 1979, 32:5-II.

II. Qi X, Bakht S, Quin B, Leggett M, Hemmings A, mellon F, Eagles J, Werck-Reichart D, Schaller H, Lesot A, Melton R, Osbourn A: A different function for a member of an ancient and highly conserved cytochrome P450 family: From essential sterols to plant defense. PNAS 2006, 103:18848-18853.

12. Penmetsa RV, Cook DR: Production and characterization of diverse developmental mutants of Medicago truncatula. Plant Phys 2000, I 23:1387-98.

13. Trinh H, Barker D, Ratet P: EMBO Practical course on the New Plant Model System Medicago truncatula november 19 december Ist 200I. [http://www.isv.cnrs-gif.fr/embo0l/manuels/ pdf/module2.pdf].

14. Xiao K, Harrison MJ, Wang Z): Transgenic expression of a novel M. truncatula phytase gene results in improved acquisition of organic phosphorus by Arabidopsis. Planta 2005, 222:27-36.

15. Balestrazzi A, Gonfalonieri M, Odoardi M, Ressegotti V, Allegro G, Tava A, Carbonera D: A trypsin inhibitor cDNA from a novel source, snail medic (Medicago scutellata $L$.): cloning and functional expression in response to wounding, herbivore, jasmonic and salicylic acid. Plant Science 2004, 167:337-346.

16. Anè JM, Zhu H, Frugoli J: Recent advances in Medicago truncatula Genomics. Int J Plant Genomics 2008:256597.

Publish with Bio Med Central and every scientist can read your work free of charge

"BioMed Central will be the most significant development for disseminating the results of biomedical research in our lifetime. "

Sir Paul Nurse, Cancer Research UK

Your research papers will be:

- available free of charge to the entire biomedical community

- peer reviewed and published immediately upon acceptance

- cited in PubMed and archived on PubMed Central

- yours - you keep the copyright
BioMedcentral 